\title{
浅析如何培养艺术设计专业学生的创新能力
}

\author{
张睦浛 \\ 赤峰第一职业中等专业学校 \\ DOI:10.32629/jief.v2i10.2371
}

[摘 要] 艺术设计是艺术、科学和技术的结合, 具有整体特征和特点。跨学科设计师应具有创造性和创造性。如果。那个艺术设计人才培养 的关键是创造性思维。本文就如何培养艺术设计专业学生的创新能力进行了分析。

[关键词] 艺术设计; 创新能力; 培养模式

中图分类号: 1561.074 文献标识码: A

设计是一项很有创造性的活动, 是一门专门研究创造性的学科。人 类艺术与设计专业是设计学科的一个目标, 其基本目标是培养具有自主 创新能力的设计人才。目前, 创新发展与大学发展存在一定差距。为了 尽快弥合这一差距, 必须在实践研究的基础上, 建立艺术类大学生自主 发展创新能力的新模式。高校设计旨在促进地方高校艺术设计专业的可 持续发展, 满足地方经济文化建设对高校艺术设计专业发展的迫切需要

\section{1 艺术设计专业发展现状}

改革开放以来, 艺术与设计开始在中国的大学里开展。高等院校开 设艺术设计专业。其中有很多学生对文化课程不感兴趣, 选择自己的专 业, 艺术设计是一种艺术结合科学技术发展的跨学科工程, 培养艺术设 计人才是一项系统工程, 这就需要综合运用哲学、社会和文化知识。然 而, 文化艺术与设计学院强调学生的专业精神, 文化课程要求减少, 学 生学习艺术上的时间增多。忽视文化教育, 强调艺术表现力, 是许多高 等教育课程普遍存在的问题。

\section{2 创新性和应用性相结合}

设计教育的首要任务是培养和解放学生的设计创造力, 帮助他们建 立形象思维、逻辑思维和创造性的工作方法体系。设计创作的过程中, 要注意定位的正确性、设计创造力、综合评价的形式表达, 逻辑思维能力, 如创作、选择、修改和设计元素的组织, 创建国家相关知识的培养和创造 的目的以及应用程序的能力。设计艺术的生命力在于创新与应用的完美 结合。设计艺术是一种新的创作活动, 其应用目的十分明确, 离不开社 会应用。这不同于自然科学和社会科学的基础理论研究。设计艺术从创 作之初就必须明确其基本功能、应用目的、市场需求和服务对象等要求。 首先, 要不断了解社会、企业和客户的需求, 增强创新意识, 适应不断 变化的设计趋势。由于设计艺术的成就与工业生产和社会经济的关系, 必须考虑企业的经济效益和社会效益。因此, 创新设计不仅要具有艺术 性, 更要具有科学性、合理性和实用性。其次, 增强学生的创新意识和 观念, 同时扩大知识面, 提高文化理论的修养。

\section{3 艺术设计专业学生创新能力培养的原则}

整体性原则。培养学生创新能力是一个整体结构, 结构越完整, 功 能越完善。艺术设计专业学生创新能力的培养需要创新意识与创新能力 协调发展, 创新态度、创新思维能力与创新技能共同发展, 形象思维与 创新思维协调发展。

发展性原则。创新能力教育是一个动态的、不断发展的过程, 是一 种顶级的教育艺术。它的形成过程必须经历一个从无到有、从低级到高 级、从简单到复杂的过程。创新能力教育的发展是无止境的, 是一个终 身学习的过程。

\section{4 构建 “教” “学”互动型自主创新能力培养新模式}

改善当地大学艺术设计专业学生的自主创新能力, 必须根据具体问 题, 把握好 “教” 与 “学” 的目标, 构建一个相对完善的自主创新能力培 养模式, 让学生意识到多维的相互交流学习, 激发主动的艺术设计专业学 生的自主学习, 发挥学生的潜力的个性, 提高学生的创新意识, 创新思维 和创新能力与个性, 使学生找到自我实现、自我创新、自我完善的良性
发展路径。当地高校而言, 实际的建设模式, 培养艺术设计专业的自主创 新能力需要关注 “教学” 模式的变换, 改变 “学习” 的概念, “教” 与 “学” 之间的交互和改善教学环境。

4.1 教学方法的转变。我们必须打破传统的教学模式和教学方法的 采用启发式提问等互动情况、分享经验和团队讨论, 以促使学生超越传统 思维和创新的壁垒, 在他们的思维方式。通过创新的教学方法, 学生可以 体验解决问题的过程, 积极寻找问题的解决方案, 激发自主学习的热情, 培养独立思考和探索的能力。例如, 在设计情节、场景或故事的过程中, 引导学生善于发现、分析和解决设计中的问题。师生交流设计思想、经 验和体会, 使学生在动态中得到启发, 使教与学实现平等、民主、和谐、 独立的平衡, 从而提高学生的自主创新能力; 小组讨论教学的实施使学 生能够更充分地表达自己的想法, 提高了学生管理设计项目的能力和组 织设计团队的能力。通过 “教学” 方法创新, 提高学生的创新意识、创 新思维、创新技能和创新人格, 为 “学习” 的自主性提供指导和启发。

4.2 “学习” 的概念已经改变了。要改变学生的学习态度, 在教师的 指导和启发下积极学习设计知识, 充分发挥学生的潜能, 努力探索新的思 路和方法, 不断发现、分析和解决设计中的新问题, 引导学生的思考和探 索更深入。通过创新教学方法和教师指导, 让学生明确自己学习过程中的 主体地位, 增强学习的责任感和使命, 培养自主探索、分析 (解释), 独立判 断, 独立能力的讨论, 到自我实现, 突破和创新的良性发展道路。自主学习 能力的培养需要良好的教学氛围: 一是确保学生在学习中的主导地位, 打 破常规礼仪习惯的束缚; 第二, 营造轻松的学习环境和氛围, 学生可以自 由辩论, 平等表达自己的设计观点、想法、概念和想法; 三是允许提问, 学生可以自然地表达意见, 表达想法, 表现个性; 第四, 学生与学生、学 生与教师共同组成设计团队, 集体讨论、头脑风暴, 确保学生与教师在讨 论中有高度的参与, 实现 “教” 与 “学” 的全面互动。第五, 加强文化知 识学习, 增强学生自身文化底蕴, 为增强创新设计文化理念提供文学内涵。

4.3 改善教学环境。教学环境是影响美术设计专业学生素质的重要 因素。教学环境包括教学督导、教学条件、师资力量、教学设备、教学 管理、教学实践、教学理念、教学目标、教学定位等要素。改善教学环 境需要大量的人力、物力和财力, 实施难度也很大。为艺术设计专业学 生构建一个完善合理的教学环境, 培养学生的自主创新能力, 还需要各 方的共同努力。

高等艺术设计教育必须努力把握时代发展的步伐和产业发展的方 向。在未来的教育中, 要不断探索新的教学方法和经过验证的培训科目, 不断提高艺术设计教育的实践效果，培养适应时代发展的人才。

\section{[参考文献]}

[1] 赵雅婷. 数据可视化大屏艺术设计 [J]. 艺术品 鉴,2020(27):100-101.

[2] 李静瑶. 解析现代艺术设计发展新趋势 [J]. 艺术品 鉴,2020(27):38-39.

[3]张岩, 孟春荣. 高校艺术设计专业人才培养模式的改革与创新 [J]. 教育教学论坛,2020(40):137-138. 